\title{
The Impacts of Platform Quality on Gig Workers' Autonomy and Job Satisfaction
}

\section{Sangmi Kim \\ University of Michigan \\ School of Information \\ Ann Arbor, MI 48109, USA \\ sangmik@umich.edu \\ Elizabeth Marquis \\ University of Michigan \\ School of Information \\ Ann Arbor, MI 48109, USA \\ ebmorris@umich.edu \\ Rasha Alahmad \\ University of Michigan \\ School of Information \\ Ann Arbor, MI 48109, USA \\ rashama@umich.edu}

Permission to make digital or hard copies of part or all of this work for personal or classroom use is granted without fee provided that copies are not made or distributed for profit or commercial advantage and that

copies bear this notice and the full citation on the first page. Copyrights for third-party components of this work must be honored. For all other uses, contact the Owner/Author.

CSCW '18 Companion, November 3-7, 2018, Jersey City, NJ, USA C) 2018 Copyright is held by the owner/author(s).

ACM ISBN 978-1-4503-6018-0/18/11.

https://doi.org/10.1145/3272973.3274050

\section{Casey S. Pierce} \\ Ann Arbor, MI 48109, USA \\ cbspierc@umich.edu \\ Lionel P. Robert Jr. \\ University of Michigan \\ ol of Information \\ Ann Arbor, MI 48109, USA \\ lprobert@umich.edu \\ University of Michigan
}

USA


research has found that gig workers have expressed a lack of satisfaction with their jobs in this new sector [11]. Satisfaction can be defined as the positive affect or valance associated with a particular activity [10]. Yet, we know relatively little about the factors which lead to gig workers' job satisfaction.

On one hand, many scholars have suggested that the "platformization" of work has contributed to the lack of job satisfaction in the gig economy [11].

Platformization is described as replacing traditional managerial roles with algorithm-based management through digital system, such as mobile applications [ 7]. Research has suggested that platforms driven by algorithms lead workers to perceive limited control over the platform and less work satisfaction [6].

On the other hand, prior literature on information systems in traditional organizations has suggested that information systems can empower workers and promote job autonomy and satisfaction [4]. In particular, systems that are high in platform quality have been linked to positive worker outcomes in many settings [5]. For gig workers, the platform is a vital information and communication technology which assigns and coordinates their work activities with their platform company and their customers. Thus, we argue that it is important to understand the quality of gig economy platforms and its impacts on job autonomy and satisfaction of gig workers.

To do so, we draw on the concept of system and information quality from prior research [3] and reconceptualize it as "platform quality". Platform quality is defined as the perceived quality of work platforms, comprised of system quality and information quality
(See Figure below). System quality indicates sophistication and flexibility of systems, to what degree systems well-integrated and short time-lagged, and easy to learn and make changes [3]. Information quality indicates the quality of information content and format, to what degree information delivered through information systems is accurate and useful in workers' jobs, and its format [3].



Figure. Construct of Platform Quality

To advance our understanding of the impact of platform quality on gig worker outcomes, this paper has three objectives. First, we introduce the concept of platform quality. Second, we examine its impacts on job autonomy and satisfaction of gig economy workers. Finally, we discuss the implications of platform quality and its possible applications in future research. In sum, we hope to contribute to the literature by proposing "platform quality" as a core construct to understand job autonomy and satisfaction of gig workers.

\section{Method}

We conducted a survey study, sampling Uber drivers through a Qualtrics panel. The survey included measurement items of perceived platform quality, job satisfaction, and job autonomy that are adopted from 


\section{Measurement items:}

Scored on a 5-point Likert scale except working hours

\section{- Platform quality} measures were comprised of 9 system quality (flexibility, sophistication) and 8 information quality items (content, format) [3] (e.g., "The Uber driver app responds quickly to my online inquiry", "Information that I obtain from the Uber driver app is accurate").

- Job satisfaction was measured using 4 items [2] (e.g., "All in all, I am very satisfied with my current job as an Uber driver").

- Job autonomy was measured using 4 items [1] (e.g., "My job as an Uber driver is left to $\mathrm{me}^{\prime \prime}$ ).

- Job dependency was measured using 4 items drawn from [9] (e.g., "My income from my job as an Uber driver is important to me and my dependents").

- Working hours per day and work days per week were asked to average working hours per week. prior studies. In addition, we asked background information, such as working hours per week and job dependency (See details in the side bar). Our data included a total of 112 responses after removing incomplete responses. The average age of respondents was 32.77 years old, ranging from 18 over 73 years, and $52.55 \%$ were female.

\section{Results}

First, before testing the relationship between platform quality and job autonomy and satisfaction of gig workers, we evaluated the reliability of measurement items of platform quality. All of the Cronbach's alpha values of the sub-components were above 0.8 . In addition, in order to understand impacts of platform quality on worker outcomes, we analyzed the data by performing regression analysis. Dependency of household income and working hours per week were controlled in the analysis.

\begin{tabular}{lcccc}
\hline \multicolumn{2}{c}{ Job Autonomy } & \multicolumn{2}{c}{ Job Satisfaction } \\
& Controlled & Full & Controlled & Full \\
\hline Constant & $2.56^{* * *}$ & $1.16^{* *}$ & $2.70^{* * *}$ & $1.09 * * *$ \\
\hline Control Variables & & & \\
Dependency & $0.31^{* *}$ & 0.14 & $0.34 * *$ & 0.14 \\
Working hours & $0.01^{*}$ & 0.00 & 0.00 & -0.00 \\
\hline Predictor & & & & \\
Platform quality & & $0.52^{* *}$ & & $0.59^{* *}$ \\
\hline$R^{2}$ & $0.12^{* *}$ & $0.36^{* * *}$ & $0.08^{* *}$ & $0.37^{* * *}$ \\
$R^{2}$ Change & & $0.24 * * *$ & & $0.29 * * *$ \\
$F$ & $7.11^{* *}$ & $20.52^{* * *}$ & $4.96 * *$ & $21.10^{* * *}$ \\
\hline
\end{tabular}

Table: Results of analysis. Note. $N=112$; Platform quality: $M=4.07, S D=0.84$, Autonomy: $M=3.83, S D=0.81$, Satisfaction: $M=3.96, S D=0.87$, Dependency: $M=3.83, S D=0.81$, Working Hours: $M=26.37, S D=20.85 ; * p<.05, * * p<.01, * * * p<.001$
The results show that in the Uber driving context, platform quality has a significantly positive impact on job satisfaction and job autonomy respectively (See details in Table). In other words, platforms with flexible and sophisticated quality of systems and accurate and consistent information are likely to improve workers' autonomy and satisfaction.

\section{Discussion}

\section{Contributions}

This study offers several contributions to both research and design concerning the potential importance of platform quality. First, this study contributes to the literature on gig economy by identifying an important predictor of gig economy worker's job autonomy and satisfaction, which is platform quality. These results although preliminary offer insights into how to address the problems of unhappy gig economy workers. Second, these findings also contribute to design by highlighting the need to ensure that gig economy platforms are designed to sufficiently address platform quality. For example, gig platforms are required to offer systems high in flexibility and sophistication and information with relevant and useful contents and formats so that workers in the platforms have greater autonomy and satisfaction.

\section{Future Research}

Future research should examine the potential mediators between platform quality and job autonomy and satisfaction. For example, the impacts of platform quality might flow through decreases in cognitive load or increases in perceived organizational support. Either could be important mediators but their implications for research and design would vary greatly. Future research might also examine how the needs of platform 
quality might vary across gig economy platforms. While the gig economy mostly operates on platforms to manage tasks and workers, each platform is designed based on its own algorithm developed to do the job in the particular context. For example, in this study we examine Uber drivers but the system and information needs of Airbnb hosts may be significantly different.

\section{Conclusion}

The gig economy is becoming increasingly important but little is known about how to promote feelings of job autonomy and satisfaction among gig economy workers. This study is an important starting point in our understanding of how to promote positive workers' outcomes in the gig economy. Nonetheless, future research is needed to build on these ideas and expand our understanding.

\section{References}

[1] Augustine O. Agho, James L. Price, and Charles W. Mueller. 1992. Discriminant validity of measures of job satisfaction, positive affectivity and negative affectivity. Journal of Occupational and Organizational Psychology 65, 3: 185-195.

[2] Robert Eisenberger, Jim Cummings, Stephen Armeli, and Patrick Lynch. 1997. Perceived organizational support, discretionary treatment, and job satisfaction. Journal of applied psychology 82, 5: 812.

[3] Narasimhaiah Gorla, Toni M. Somers, and Betty Wong. 2010. Organizational impact of system quality, information quality, and service quality. The Journal of Strategic Information Systems 19, 3: 207-228.

[4] Kailash Joshi and Arun Rai. 2000. Impact of the quality of information products on information system users' job satisfaction: an empirical investigation. Information Systems Journal 10, 4: 323345.
[5] Jung-Yu Lai. 2006. Assessment of employees' perceptions of service quality and satisfaction with ebusiness. International Journal of Human-Computer Studies 64, 9: 926-938.

[6] Mareike Möhlmann and Lior Zalmanson. 2017. Hands on the wheel: Navigating algorithmic management and Uber drivers' autonomy. In Proceedings of the International Conference on Information Systems (ICIS '17), 1-17.

[7] Geoffrey G. Parker, Marshall W. Van Alstyne and Sangeet Paul Choudary. 2016. Platform Revolution: How Networked Markets Are Transforming the Economyand How to Make Them Work for You. W.W. Norton \& Company, New York, NY.

[8] Pew Research Center. 2016. Gig Work, Online Selling and Home Sharing.

[9] Anne Richter, Katharina Näswall, Claudia BernhardOettel, and Magnus Sverke. 2014. Job insecurity and well-being: The moderating role of job dependence. European Journal of Work and Organizational Psychology 23, 6: 816-829.

[10] Lionel P. Robert and Sangseok You. 2018. Are you satisfied yet? Shared leadership, individual trust, autonomy and satisfaction in virtual teams. Journal of the Association for Information Science and Technology 69, 4: 503-513.

[11] Alex Rosenblat and Luke Stark. 2016. Algorithmic labor and information asymmetries: A case study of Uber's drivers. International Journal of Communication 10: 3758-3784.

[12] Michelle Singletary, 2018. Your retirement may be saved by a side hustle. Retrieved June 30, 2018 from https://www.washingtonpost.com/news/get-

there/wp/2018/06/04/your-retirement-may-be-savedby-a-side-hustle/?utm_term $=.8 \mathrm{a} 28 \mathrm{e} 10 \mathrm{c} 42 \mathrm{fc}$ 